\title{
Study on Cooperative Mode Between Food \& Beverage Department and Bank
}

\author{
Xudong Guo \\ Tourism and Historical Culture College \\ Zhaoqing University \\ Zhaoqing, China
}

\author{
Haiming Chen \\ Tourism and Historical Culture College \\ Zhaoqing University \\ Zhaoqing, China
}

\author{
Zhixian Liang \\ Tourism and Historical Culture College \\ Zhaoqing University \\ Zhaoqing, China
}

\begin{abstract}
From the angle of hotel, the article expounds the hotel food and beverage department and bank cooperative mode, the cooperative mode will be divided into three broad categories through the relevant site data and interviews. Three types of cooperative mode focus on six key points: the hotel's choice of bank, dining time limit, the duration of cooperation, limitation to the number of meal, booking channel limited and preferential margin. Each point and the different combination between each point may have impact on the cooperative mode between hotel food and beverage department and bank. The article point out that the cooperative mode may have some problems, such as booking channel problem, number limitation problem, food quality and authenticity problem. It suggests that to make the cooperative mode running better, the hotel can strengthen the construction of hotel information system, or improve the quality of hotel contact with Banks, or reduce the gap of food quality and dining environment between hotel and customer expectation to ensure the reality of the cooperation and to give customers real high-end dining experience.
\end{abstract}

Keywords-Food \& Beverage department; bank; cooperative mode; expectations' gap; high-end dining experience

\section{INTRODUCTION}

\section{A. Background and Significance}

According to the bank of China's Payment systems running the overall situation in the first quarter of 2016, we know that, in the first quarter of 2016, China's bank card consumption is steadily rising. In terms of bank card consumption, although affected by the economy at home and abroad, Chinese consumer confidence has fluctuated in the first quarter in 2016, but the actual consumption of Chinese bank cards still maintain good growth [1]. Issued by China Unionpay bank cards 2016 holiday consumption data shows that bank cards consumption focus on mass catering [2]. Holders of bank cards, credit card can enjoy discounts at fix restaurant that help promoting their sales. More and more catering enterprises, especially hotels and resorts catering sector are gradually involved.

\section{B. Trends}

According to literature review and resource online, the cooperative mode focused on the following aspects:

1) From the angle of bank, studying on the cooperation between banks and enterprises: Zang Jingmin (2011) noted that the cooperation between banks and enterprises was still concentrated in loans, and proposed a way to build a new bank - enterprise cooperation mode in China[3]. In addition, $\mathrm{Xu}$ Jianzhong (2011) put forward the route choice of innovation model of bank-enterprise cooperation [4]. XU analyzed the actuality and the modern new-type relationship of cooperation between banks and enterprises, and probed into the problems existing in the cooperation between banks and enterprises.

2) From the angle of bank ,studying on bank card business problems: On the one hand, Wang Yuping (2003) noted that preference merchants are signing with the issuing bank receiving bank card consumption operational units and are an important channel for banks to obtain high yields, thus, developing efficient and high-quality merchants plays a key role on the bank card business problems[5]; Chen Yongjun (2000) noted that in the bank card service system, how to handle well the relationship between issuing bank and the merchant is of significance[6]. Chen Yongjun and Wang Yuping focus on the relationship between banks and merchants maintenance problems. On the other hand, ZuoLin(2009)said that in recent years, the commercial bank and China Unionpay bank launched cards preferential merchant services.Card holder can enjoy discounts and other value-added services at preference merchant [7]. Zuo Lin also focus on the problem of preference merchant.

In summary, the current study focus on the banks, study on banks and enterprises in macro aspect, pay attention to the 
development of bank card business problems and preference merchant problems. But there is lack of study on the cooperative mode between hotels and banks focus on the enterprises, especially in a further narrow perspective, indepth study of hotel F\&B department and bank cooperation. As one of the bank's preference merchants, how hotel cooperate with banks.

\section{The Classification of COOPERATIVE Mode}

Information of food and beverage concessions from hotel official website focus on the discount for hotel members for a limited time only (mainly concentrated in Chinese tea time), special planning activities (such as meal preferences, fitness for a particular dish Preferences).Meanwhile there are little or no provision in cooperation with banks to provide preferential information. The information about the cooperation between F\&B department and bank is obtained from the bank's relevant sites "Table I" and from an interview (Interviews and the document will be referred to in the third part of the Cooperative Mode feature).

From "Table I", the cooperative mode between F\&B department and bank is mainly divided into the following three categories

\section{A. Special Bank Card + No Specified Meal Period + Discount (+ Long-term /Short-term Cooperation)}

"A Special Bank Card + No Specified Meal Period + Discount (+ Long-term /Short-term Cooperation)" means: special bank card holders can enjoy the specified discount in any of the cooperative hotel F\&B department at any operating times (Special holidays does not apply and is not used with other offers), such as the cooperative mode between Guangzhou Holiday Inn, Millennium harbourview hotel Xiamen and China Construction Bank. Customer can enjoy the benefits at any time.

\section{B. Special Bank Card + Specified Meal Period + Discount (+ Long-term /Short-term Cooperation)}

"Special Bank Card + Specified Meal Period + Discount (+ Long-term /Short-term Cooperation)" means: special bank card holders can enjoy the specified discount in a specified period of operating time (Special holidays does not apply and is not used with other offers), such as the cooperative mode between the Westin Shenzhen Nanshan known western and Pingan Bank. Customers can select arbitrary period from October 1, 2016 to March 31, 2017 to enjoy dining discount.

\section{Special Bank Card + Specified Meal Period + Booking Channel Limit + Number limit + Discount $(+$ Long- term /Short-term Cooperation )}

"Special Bank Card + Specified Meal Period + Booking Channel Limit + Number limit + Discount $(+$ Long-term /Short-term Cooperation)" means: special bank card holders can enjoy the specified discount in a specified period of operating time by channels of a specified reservation and a limited number of meal (Special holidays does not apply and is not used with other offers), such as the cooperative mode between Shangri-La hotel and Bank of China. Cardholders can enjoy "The two men, One Free" buffet concession by telephone reservation earlier in the week on Thursday from January 8, 2017 to June 30, 2017, Each customer can book up to two copies and there are a limitation to the number of daily meals.

\section{CHARACTERISTICS OF COOPERATIVE MODE}

Based on the cooperation pattern classification, the author believes that the classification concerned: The choice of banks, dining time limited, the number of customers, booking channel limited and preferential margin. In order to understand the characteristics of cooperation between hotel F\&B department and bank, in January 2017, the writer interviewed a director of the High star-level hotel restaurant in Foshan Shunde (The hotel was founded in 2009, and the director is one of the establishment employees of hotel, now, he is the person in charge for the hotel west restaurant. The interview reads as follows:

\section{Outline of interviews:}

Q1: what discounted concession in formation does the cooperation offers?

Q2: do customers need a reservation? Why can be booked by phone only?

TABLE I. INFORMATION ABOUT THE HOTEL AND BANKING COOPERATION

\begin{tabular}{|l|l|}
\hline \multicolumn{1}{|c|}{ Hotels\& Banks } & \multicolumn{1}{c|}{ Information } \\
\hline $\begin{array}{l}\text { Shangri-La hotel } \\
\text { Bank of China }\end{array}$ & $\begin{array}{l}\text { "Two men, one free"! From January 8, 2017 to June 30, 2017, with Bank of China 62 at the } \\
\text { beginning of Unionpay standard credit card customers can enjoy the hotel buffet every } \\
\text { Thursday " Two men, One Free " concession. Phone booking only }\end{array}$ \\
\hline $\begin{array}{l}\text { Guangzhou Holiday Inn } \\
\text { China Construction Bank }\end{array}$ & $\begin{array}{l}\text { 1.TheCCB private banking, wealth and diamonds, platinum credit cards; Consumption can } \\
\text { be enjoyed at Guangzhou Holiday Inn Quan cafe dinner buffet 80 percent discount } \\
\text { 2.Millennium harbourview hotel Xiamen enjoy 90 percent discount on food and so on } \\
\text { 3.Long-term cooperation } \\
\text { 4.Not used with other offers and are not used on holidays }\end{array}$ \\
\hline $\begin{array}{l}\text { ShanDongXixiaGuodu Hotel } \\
\text { Agriculture Bank of China }\end{array}$ & $\begin{array}{l}\text { 1.Catering 90 percent } \\
\text { 2.Long-term cooperation }\end{array}$ \\
& \\
\hline
\end{tabular}




\begin{tabular}{|l|l|}
\hline \multicolumn{1}{|c|}{ Hotels\& Banks } & \multicolumn{1}{c|}{ Information } \\
\hline Holiday Inn Meizhou Jiazhou & 1.Peony Credit Card platinum, gold, card holders enjoy a 85 percent discount on F\&B \\
$\&$ & consumption \\
Industrial and Commercial Bank of & 2.Long-term cooperation \\
China & 3.Shark, Yan,soups, seafood,game,drinks, except for specials \\
\hline Westin Shenzhen Nanshan & 1.Brushed platinum, diamond credit card safely, every monday through sunday to the \\
$\&$ & Westin Shenzhen Nanshan taste restaurant to enjoy buy one get one free buffet dinner \\
Pinan Bank & 2.Time : 2016-10-01 to 2017-03-31 \\
\hline
\end{tabular}

Q3: Why not choose a long-term cooperation?

Q4: Why there is a limitation to the number of meal and mealtimes?

Q5: What does it matter the margin of preference?

Q6: Do you have any special requests about the choice of banks?

Repeat the problem of uncertainty.

Interview:

Q: Could you tell me something about the cooperation between hotel and bank. Like what discounted concession information hotel will offer to customers?

A: Cooperation with the bank on March 2016 to May 2016. Credit card holders of Shunde XX bank can enjoy the buffet " Two men, ne Free " concession through telephone reservations a week in advance of next Tuesday or Thursday, Do not accept the book of the Week for the Week .

Q: Must book?

A: Yes, Only (accept) phone book

Q: Why?

A: No need to open other ways of booking because reservation is not so much. And it lasts only two months

Q: Won't cooperate any longer? point.

A: It depends on the performance, this is an important

Q: why not make this cooperation a permanent arrangement?

A: If it is a long-term cooperation, we can't offer amount of discount. But when there is a downturn of our restaurant, we will offer a relatively favorable discount to attract a large number of customers, especially to motivate the local customers.

Q: what is the extent of the discount of the long-term cooperation?

A: Discounts offered of the long term cooperation will not be lower than the discount offered to the hotel members, like the Members privileges and also will not be lower than the quantity discounts (in hotel it means the number of customers). But if it is a time limited promotion especially is a promotion of high star level hotel, it would have been different, and it can attract customers in a short time.

Q: Why there is a limitation to the number of meal and mealtimes?
A: One reason is that the hotel can accommodate a limited number of dining, on the other hand, the more restriction, the more attention.

Q: Why choose Shunde xx bank such local bank rather than choose the Bank of China, China Construction Bank and other banks to cooperate?

A: There are no special requirements to choose a bank when it is a long-term cooperation, but there will be some special demands for short-term cooperation, called time limited cooperation. We will choose local bank, especially the famous and popular local bank, in order to attract and motivate the local customers.

Q: According to what you just said, normally, if there is a long-term cooperation, the discount will lower than the discount offered to the time limited cooperation and it may because of the attraction to the customers. In addition, it can play a positive role in a hotel's business downturn if there is time limited cooperation in a short period of time. Is that right?

\section{A: Yes.}

Q: Thanks for agreeing to do this interview.

Therefore, based on the interview, the author makes a conclusion on the Characteristics of the cooperative mode:

\section{A. Preferential Margins Is Related to the Duration of the Cooperation}

Based on the interview, the author can make a conclusion that preferential margins are related to the duration of the cooperation. In general, if it is a long-term cooperation with bank, hotel will offer the discount not less than the members discounts and the quantity discounts (in hotel it means the number of customers). However, when there is a short - term cooperation with banks in particular a short-term cooperation with dining time limited, the hotel's discounts will be given greater than the same period of the implementation of other concessions.

\section{B. Number of Dining Customers Is Related to Duration of the Cooperation and Preferential Margins}

Generally, if there is short term cooperation with a specific mealtime, hotel will have a limitation to the number of mealtime. And if it is a long-term cooperation, it will not have a number limitation. When there is a time limitation to the cooperation, The Preferential margins affect the number of mealtime. If there is amount of discount in a short time, it will attract a large number of customers, so, hotel should make a commitment with the bank of the maximum received number of customer. 


\section{Tend to Cooperate with the Bank in a Market Downturn}

1) Tend to cooperate with the bank in a market downturn: Service enterprises can't like industrial enterprises which can store products from off-season to the peak season [8]. So, when there is a market demand downturn, the demand management will be carried out in the hotel. Therefore, there will be price promotions to attract customers, to increase hotel production sales, and to improve the utilization of its facilities in the off-season [9].

2) Hotel tends to choose a cooperative mode with time limitation in a market downturn: In general, the purpose of short-term cooperation with the bank is to deal with the business downturn and is the response measures to its offseason period. In the way, it can attract a large number of customers coming in the short term to Balance low and peak seasons of hotel.

\section{The Length of Cooperating Time Influences the Choice of Hotel for Cooperative Banks}

As noted above, the purpose of short-term cooperation with the bank is to deal with the business downturn. In order to attract a large number of customers coming in the shortterm; it is also a response to the low season or off-season period. In such situation, hotel had better choose a local bank with large number of customers, thus, the hotel can quickly access to the potential customers while save a number of advertising cost .As for the long term cooperation, to attract a large number of customers in a short time is not the purpose of hotel, so, discounts offered by hotel is lower than the short term cooperation's and is lower than the same period concessions of hotel food and beverage. Therefore, there are no special requirements for the choice of a cooperative bank.

\section{E. To Select a Time Limitation Cooperative Mode is More Advantageous to Increase the Appeal of the High Star- level Hotel Catering}

1) Time limitation cooperative mode increase the appeal of the high star-level hotel catering: High star-level hotel catering is most attractive to local customers, but because of the spending power, these local customers were be restricted. Time limitation cooperative mode offer amount of discounts might make the most of customers' expectation, attracting the local customers to come to counsel or dine. And the mode of "short term cooperation + specific mealtime" adds attention and attraction to the cooperating activity.

2) High star-level cafeteria is more suitable for shortterm preferential cooperation with the bank: The hotel's buffet food must be as finished goods supplied during business hours. At the end of the day's operating times, the food or some used food must be disposed of .when there is a business down turn to the restaurant, it must cause a waste and even rising cost. Hotel food and beverage department as the important creators of profits must be carried out in all aspects of cost control, seeking to win the maximum profit with minimum costs [9]. Thus, the hotel should make price promotions to attract customers and to increase their sales during the downturn. So, when there comes short term cooperation with the bank, hotel can protect the normal sales and invigorate the "would have been wasted inventory "to give consumers a cost-effective dining experience.

\section{$F$. Cooperation with a Lot of Concessions Is a Manifestation of High-end Catering Gradually Becoming Common(Popular)}

In China's two sessions, held in March 2017, Huizhou Tourism Bureau presented on the recommendation on increasing the intensity of the hotel and catering industry support. This suggests that, in recent years, catering artificial, ingredients, energy and other costs continue to rise and most medium-sized food companies faced with the dilemma of profit or even a loss situation, but the entire consumer trends leading transition in hotels. Trying to keep up food prices is difficult, what the boss can do is push down profits. Xiangeqing hotel Xuzhou Chairman Lian $\mathrm{Lu}$ pointed out high-end restaurant in transition is the general trend. What hotel can do is to be flexible when faced with a fait accompli market. The reality of the market is that many high-end hotels are cutting the price while the mass catering is quietly raising prices. In fact, if you are a reasonable consumer in high-end restaurant, the benefits you can enjoy will far outweigh the benefits received in the general dining establishments. This is one of the biggest advantages of highend restaurant in transition [10]. High star-level hotel food and beverage promotional measures during the off-season period just cater to populist trends, it can help guide the public to open the door for high-end catering enterprises.

\section{Problems In COOPERATIVE Mode}

In order to collect more information about the cooperation, the author makes an interview with the head of a High star-level hotel restaurant in January 2017. The respondent said, problem exist in short-term cooperative activities with big discounts and dining time limited or number of mealtime limited. Therefore, the author collects the relevant information about this mode.

In a report on the activities of the hotel and banking cooperation of the customer's reservation record (March 2016-May 2016). The author found that, it notes messages of 162 guests' feedback information from March to May. There are 67 guests reflect the intended phone went dead, 60 guests cannot be scheduled to participate in promotions due to the phone went dead, thus even doubt the authenticity of promotions. And 30 guests pay attention to the food quality issues while 5 guests made other feedbacks. Proportion of issues is shown in "Fig. 1".

In terms of food quality, 6 guests were concerned about dining environmental issues, 24 guests were concerned about if there will be a gap of food quality after discounted. Proportion of these two issues is shown in "Fig. 2".

According to the data provided in "Fig. 1" and "Fig. 2", the author concludes that the cooperative mode may have the following problems. 


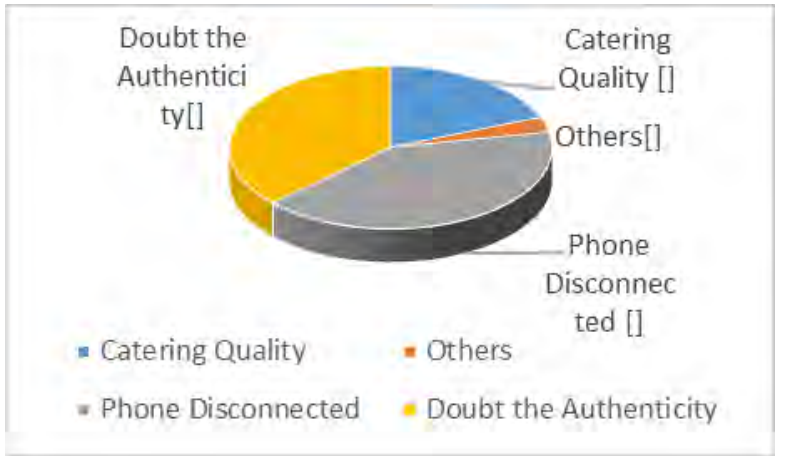

Fig. 1. The proportion of feedback.

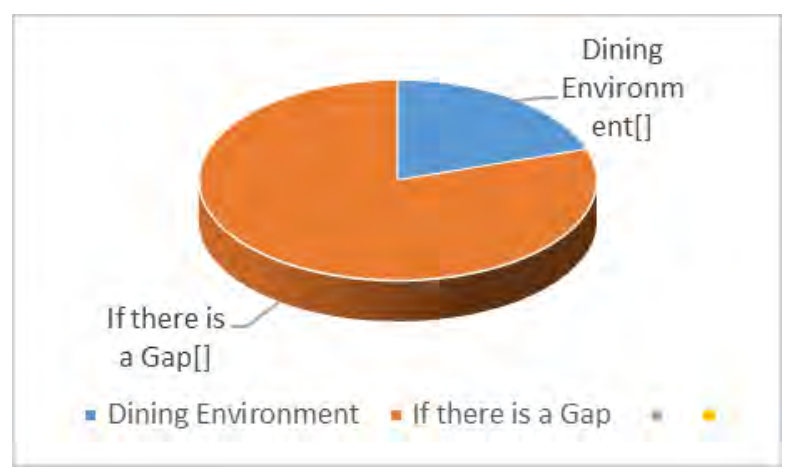

Fig. 2. The proportion of catering problems.

\section{A. Single Channel of Booking}

If customers are concentrated in a limited time period to make hotel reservation calls, the network cannot access so many customers at once that it will display a waiting state, like stay on the phone will display the hotel reservation line is busy or in a silent mode. Restaurant's capacity is restricted, and fulfillment can be scheduled within a short period of time.

\section{B. Doubting the Authenticity of Cooperation}

In Single booking channels, the phone does not work combined with the limitation to the number of customers so that most of customers was unable to successfully participate in promotions. Moreover, customers who cannot participate in the preferential activity suspected the authenticity of the cooperation.

\section{Paying Attention to Food Quality}

1) If there is a huge gap after discount: Among the 30 customers, $80 \%$ customers focus on the food problems. They worried that it would exist a huge gap after discount of the kinds of foods and its quality.

2) Dining environment: Among the 30 customers guests, $20 \%$ dining customers focused on environmental issues, they were worried about the restaurant would be crowded and too noisy.

\section{The Number of Dining Customers Is Poorly Controlled}

Is it means, the more customers come to participate, the better the hotel will be in a downturn period (in an off-season period)? Actually not, the number of the dining customers should be controlled in a certain range .based on the interview; the interviewee said that in March 2016 to May 2016 because of the preferential promotions, hotel was repeatedly unable to serve the in-house guests.

\section{IMPROVED PROPOSALS}

Here are some improved proposals to deal with the potential problems

\section{A. Suggestions to Single Booking Channel}

Based on the interview, hotel is unnecessary to set up another booking channel because of short term cooperation. Thus, the author thinks that under the way of phone booking only, to open other booking channels cannot be able to ensure the fairness of promotion and it is disadvantageous to the control of the number of dining customers. What customers focus on is the active response when they are making a phone reservation, so when customers cannot connect to the hotel's telephone reservation system, what they complaint about is no response to the phone and no respond to a continuous waiting. Therefore, the author suggests:

1) Increasing investment in information technology to improve reservation system: In the case of technology possible, hotel can give such feedback to the deactivated reservation phone: The number you dialed is hosting several guests of the cooperation with bank, or there are $\mathrm{xx}$ guests in front of you waiting, or please wait here or please redial later rather than no respond to the customers.

2) Strengthening the service consciousness of the staff: Hotel should focus more on the customers of failed reservation. This type of customers will easily have dissatisfaction because of the failed reservation.in this case, the hotel staff should politely and clearly inform the information of promotions to customers, while giving more suggestion for a solution and giving the customer vent channels. Probably, the staff should skillfully seize the opportunity to recommend other food and beverage concessions to the customers, and strive to make customers psychological balance to reduce their disappointment and reduce publicity of bad word-of-mouth to hotel of the customers. Banks using the preferential merchant marketing improve customer loyalty [11]. At the same time, hotel should also strive to maintain its customers. Hotel should not only regard them as the bank's customers, but also regarded them as potential customers or even help them become reality customers for hotel.

\section{B. Suggestions to the Authenticity}

1) Strengthening links between hotel and bank: Hotel should contact the bank in time and pass the feedback to the bank to take timely action to deal with to problems. The bank can use the banking system to send information to contact the cardholder customers, giving timely explanation and suggestion on dining and order problem. Only hotel and 
bank safeguard both the guests together that the cooperation can achieve a win-win.

2) Cooperation mode offers a fair and transparent reality to the customers: During the early promotions, hotels should offer cooperative information through certain channels and undertake commitments with bank in accordance to serve the customers. Promotions in the medium term, hotel should take measure in a timely manner to respond positively to some of the problems occur during the business on the hotel web site, and welcome customers to conduct constructive criticism and supervision; the latter part of the promotions, hotel should express sincere thanks to the participated customers through certain ways, and timely obtain customers' feedback and suggestions, timely responses customers' feedback on its website.

\section{Suggestion to the Off-season Period "Overbooking” Problem}

1) Employing temporary part-timers to relief the reception and sservices: Balancing supply and demand of Human Resources noted that when human resources is overdemand, enterprise can consider employ a small number of skilled workers or employ a skills shortage of staff then make a training to them immediately in order to achieve the corporate objectives[12]. So when the hotel is overbooked during the off-season ,you can also hire part-timers to ease the day's reception and services.

2) Making a prediction on the number of customers, reserving seats and controlling the number of customers: Instead of the catering only enterprises, hotel food and beverage department also needs to receive certain amount of in-house guests. Hotel doesn't know in advance whether guests dine here or not, what hotel should do is to seize the initiative, making a trend analysis chart based on past guests dining information to measure how many seats should be reserved for in-house guests each day.

\section{Advice on the Food Quality Issues}

1) The dining environment: It is not surprised when it occurs noisy problem during the period of a short time of preferential because there is a limitation of reception to the restaurant while there is a large number of dining customers coming in a short time. How to balance the relationship need customers and hotel to work together. Hotel can communicate with the bank in advance to remind customers there may be a congestion problem during the promotional period .But hotel cannot control the customers .In this case, only if hotel do a serious dedication to their job, can the dining environment and service such related issues be dealt with.

2) When it comes to food: Hotel should give a timely response and increase customers' understanding of the promotion in their reservation or consult while reduce the gap in the actual dining experience. In addition, the hotel should also think about the purpose of the cooperation and avoid ignoring the normal operation. Besides, do well in input and analysis of the information about the cooperation, analyzing the trends of the cooperation to have a better choice on such cooperation in the future.

\section{CONCLUSION}

From the angel of hotel, study on cooperative mode between Food \& Beverage department and bank aims to help the hotel to better recognize the purpose and significance of cooperation between the two sides. And from the characteristics of each mode of cooperation with the classification of bank cooperation mode, hotel can learn that cooperative mode may have booking and catering quality and other issues, by knowing such booking and catering quality issues, hotel might do its best to take timely preventive measures to make their work better and raise the guests' satisfaction. In addition, in recent years, catering artificial, ingredients, energy and other costs continue to rise, most medium-sized food companies faced with the dilemma of profit or even a loss situation, through the study on cooperative mode between Food \& Beverage department and bank, it allows hotels to better understand the existing cooperative mode which contains a trend of high-end catering popular .Hotel should seize the chance to seek for wider and deeper breakthrough to give customers real highend dining experience.

\section{ACKNOWLEDGMENT}

Because of the limitation of time and capability, the author have had chosen an interviewee in the study on cooperative mode between Food and Beverage department and bank. Insufficient number of interviews may have an effect on the paper, but the interview the author made is typical and representative. Therefore, the paper may have some flaws, I hope more suggestions and welcome to point out deficiencies. Last but not least, thanks for support given by the entire person, sincerely!

\section{REFERENCES}

[1] Zheng Shen. Steady growth of bank card,Mobile electronic payment terminal become the mainstream [N]. Financial News, 2016-0609(006).

[2] Tang Fuyong. Play shopping holiday card into Unionpay card spending of visit shop in holidays become the consumer mainstream [N]. China Economic Times, 2016-10-10(003).

[3] Zang Jingmin. Practical thought on the establishment of the cooperative mode between bank and enterprise [J]. Journal of Shandong Agricultural Administrators'College, 2011(02): 54-55.

[4] Xu Jianzhong.Innovation of cooperative mode between bank and enterprise: A case of Jiangsu Lianyungang orient rural cooperative bank [J].Journal of Huaihai Institute of Technology, 2011(12): 74.

[5] Wang Yuping. Development and expansion of the bank card business of merchants [J]. Financial Computerizing, 2003(03): 63.

[6] Cheng Yongjun,SHI Zaisong. Bank card and the merchant [J]. China Credit Card, 2000(01): 69.

[7] Zuo Lin. China Credit Card vigorously develops bank card merchant services [J]. Finance \& Economy, 2009(24): 144.

[8] Wang Shucui, Yuyang.Service quality management in hospitality[M]. Beijing: China Travel and Tourism Press, 2013.10.

[9] Wang Lin, Tang Baiying. Hotel Management Practice [M]. Wuhan: Wuhan University Press, 2004. 213. 
[10] Zheng Wei. How high-end restaurant in transition: Visit to Xuzhou xiangeqing Lian Lu, chairman of the hotel $[\mathrm{N}]$. Xuzhou Daily, 20138-28(003).

[11] Tang Xin. How to enhance customers' loyalty by ex-gratia businesses marketing [J]. China Credit Card, 2010(12): 38-39.

[12] Cheng Weizheng,Yu Kaicheng, Cheng Wenwen. Human resource management[M]. Beijing: Higher Education Press, 2011. 54. 